\title{
Investigation of microstructure and mechanical characteristic of underwater friction stir welding for Aluminum 6061 alloy - Silicon carbide (SiC) metal matrix composite
}

\author{
Ibrahim Sabry \\ Department of Mechanical Engineering, Faculty of Engineering, Benha University, 13511 Benha, Egypt \\ Phone: +201003719980
}

ABSTRACT - Demand for metal matrix composites (MMCs) is expected to increase in these applications, such as in the aerospace and automotive sectors. Adequate joining techniques, which are important for structural materials, have not yet been developed for Metal Matrix Composite (MMCs), however. This work aimed to demonstrate the feasibility of friction stir welding (FSW) and underwater friction stir welding (UFSW) for joining $\mathrm{Al} 6061 / 5, \mathrm{Al} 6061 / 10$, and $\mathrm{Al}$ $6061 / 18$ wt. \%SiC composites have been produced by utilizing reinforce stir casting technique. Two rotational speeds, 1000 and $1800 \mathrm{rpm}$, and traverse speed $10 \mathrm{~mm} \mathrm{I} \mathrm{min} \mathrm{were} \mathrm{examined.}$ Specimen composite plates $10 \mathrm{~mm}$ thick have been successfully welded by FSW. For FSW and UFSW, a tool made of high-speed steel (HSS) with a conical pin shape was used. The result revealed that the ultimate tensile strength of the welded joint by FSW and UFSW at rotation speed $1800 \mathrm{rpm}$ for (Al 6061/18 wt. \% SiC composites) was $195 \mathrm{MPa}$ and $230 \mathrm{MPa}$ respectively. The ultimate tensile strength of the welded joint by FSW and UFSW (Al 6061/18 wt.\% SiCe composites) was $165 \mathrm{MPa}$ and $180 \mathrm{MPa}$ at rotation speed $1000 \mathrm{rpm}$ respectively. The microstructural assessment showed that due to larger grain sizes at FSW and UFSW, most of the fractures are located in the thermal mechanically affected zone (TMAZ) adjacent to the weld nugget zone (WNZ). It is observed that in failure, most of the joints show ductile features. As the volume fraction of $\mathrm{SiC}$ (18 wt.\%) increases, the friction stir welded and underwater friction stir welded efficiency decreases.
ARTICLE HISTORY

Received: $29^{\text {th }}$ June 2019

Revised: $26^{\text {th }}$ Jan. 2021

Accepted: 14th June 2021

\section{KEYWORDS}

Friction stir welding;

underwater friction stir

welding;

Aluminum matrix

composites;

tensile strength;

microhardness;

microstructural analysis

\section{INTRODUCTION}

Over the years, the use of aluminium (Al) alloys in the construction of high-strength structural components has increased, in particular in the automotive, engineering, engineering, aerospace and defence industries [1] This was motivated mainly by the need to minimise energy consumption, with its high strength and low weight characteristics, in social and industrial use. In these industries, aluminium reinforced structural parts have been used for an increasingly complex array of components [1]. Metal Matrix Composites (MMCs) are one of these reinforced materials and consist of a combination of reinforcements (metallic or ceramic additions of carbides, oxides and nitrides) in a tough metallic matrix. Various forms of reinforcements have been examined, including continuous fibres (both monofilament and multifilament), short fibres, whiskers and particulates, varying from 10-60\% by volume [2]. The percentage of reinforcement, along with the production mode, has a impact on the properties that can vary with each type of reinforcement used. Due to the wide range of properties they provide, metal matrix composites (MMCs) are emerging as important versatile materials. The near-net-shape of the particulate metal matrix composite (MMCs) can be imparted by powder metallurgy techniques [3]. Because of these features, aluminium metal matrix composites are commonly used in the sectors of automotive, aircraft, aerospace and electrical packaging. The gain here is the opportunity to adapt properties to meet particular specifications where traditional unreinforced materials are not acceptable [4]. However, their usability, highlighted due to poor durability and costly production techniques, is minimal. The combination of Metal Matrix Composite (MMCs) with traditional fusion welding techniques depraved the typical feature because the shape and chemical responses instigated for consolidation were deprecated $[5,6]$

The density difference in particle segregation between ceramic particles and the matrix process has increased. In comparison to that of the as-cast base metal of composite material, the distribution of reinforcement agents in the nugget zone is very strict to maintain. The top viscosity of the composite matrix impedes the material movement, persuading a heterogeneous dispersion of thermal stresses to decrease the joint power. The amount of heat generated mainly initiates reactions between the reinforcement phase and the aluminium alloy matrix via the traditional fusion welding process, which creates brittle intermetallic amalgams in the nugget zone.In addition, welded joints formed by the traditional fusion welding process are tractable to the porosity effect [7-10]. It is also recommended that solid-state joining techniques be used to weld al-matrix composites to eliminate this shortcoming. A solid-state welding technique for friction stir welding (FSW) has progressed as a progressed joining technique for aluminium matrix composite weldin [11,12] As the joint takes place in the solid state, a consolidation-instigated formation is consequently not present in the nugget region in friction stir welding. Therefore, all the shortcomings associated with fusion joining processes are gone [13-14]. Some 
study on friction stir welding of Al-matrix composites reinforced with various ceramic particles has been reviewed in contemporary literature [15].

AA6063/10.5wt percent $\mathrm{SiC}$ composite was produced in this experimental study using improved stir casting technique with the aid of $\mathrm{Mg}$ metal powder. Friction stir welding (FSW) was conducted at an instrument rotation rate of $1400 \mathrm{rpm}$ with a transverse instrument rate of $124 \mathrm{~mm} / \mathrm{min}$.For FSW, a cylindrical tool made of high speed steel (HSS) with a square pin shape was used. The outcome showed that the welded joint's ultimate tensile strength was $163 \mathrm{MPa}$, which was very similar to the as-cast composite matrix 's strength.During FSW, the rapid stirring action of the tool pin cracked the $\mathrm{SiC}$ particles in the solder nugget.A fine-grained structure and homogeneous dispersion of SiC particles has been observed in the weld field [16].

Underwater friction stir welding (UFSW) process is one of the modern methods in which components immersed under the liquid are welded using friction stir welding (FSW) technology. It was claimed that this groundbreaking approach had many benefits over conventional friction stir welding technology. UFSW is found to effectively regulate the heat dissipation and conduction along the weld route to create joints with enhanced mechanical properties [17]. Underwater friction stir welding and conventional friction stir welding are conducted in this research on AA 6063 pipe joints with special, designed fittings. The connectors are planned and assembled for secure keeping of the two wires. Initially, the welding criteria are calculated by running many trials to achieve standard welds. Underwater friction stir welding reported a strong tensile strength of $218 \mathrm{MPa}$ and a nugget zone hardness of $83 \mathrm{VHN}$ compared to the $201 \mathrm{MPa}$ and $65 \mathrm{VHN}$ conventional method. Flawless quality welds produced indicate their suitability for underwater friction stirring processes for welding pipes [17].

In the past, studies on flat plates made of various aluminum alloys utilizing UFSW rather than FSW presented an improvement in the ultimate tensile strength [18 -19]The applicability of UFSW to dissimilar plate metals (AA6061-T6 and AISI 304) was shown by [20]. UFSW has been effective in minimizing the aggregation of porosity and inter-metallic compounds. Researchers have effectively welded and examined. The prime findings note that high rotational velocity in UFSW has no impact on the produced heat relative to conventional FSW. In the case of UFSW a normal thermal period is an additional value. UFSW also suggests fast movement speed and tool rotational speed [21]. The effect of various welding styles, such as rotation speeds from $500 \mathrm{rpm}$ to $2000 \mathrm{rpm}$ and welding speeds from $50 \mathrm{~mm} / \mathrm{min}$ to $150 \mathrm{~mm} /$ min. Welding parameters are researched on the properties of the weld joint. Tensile strength, distribution of microhardness, fracture properties, micro-and macrostructure were evaluated for the fabricated weld joints. With the elongation measurement at $14.78 \%$, a cumulative ultimate tensile strength (UTS) value of $222.07 \mathrm{MPa}$ is achieved. It is observed that in failure, most of the joints show ductile features [22].

Work aimed to demonstrate the feasibility of friction stir welding (FSW) and underwater friction stir welding (UFSW) for joining $\mathrm{Al}$ 6061/5, Al 6061/10, and $\mathrm{Al}$ 6061/18 wt. \%SiCe composites have been produced by utilizing reinforce stir casting technique. Two rotational speeds,1000and $1800 \mathrm{rpm}$, and traverse speed $10 \mathrm{~mm} \backslash$ min were examined. Specimen composite plates $10 \mathrm{~mm}$ thick have been successfully welded by FSW and UFSW.

\section{METHODS AND MATERIALS}

In this work, 6061 / SiC Aluminum Matrix Composite(AMC) and FSW and UFSW 6061 alloy reinforced with Sic particles was used to generate AMC. A stander 6061aluminum alloy with the formal chemical composition as shown in Table 1 is the matrix. Silicon carbide $(\mathrm{SiC})$ reinforced 6061 matrix composites were developed in a top loading electric resistance muffle furnace using stir casting technique as stated in the literature[23]. The 400 mesh (40 $\mu \mathrm{m})$ was the average size of the $\mathrm{SiC}$ particles. Castings were formed by reinforcing $5 \mathrm{SiC} \%, 10 \mathrm{SiC}$ wt. \%and $18 \mathrm{SiC}$ wt. Slashed composite samples of the scale $(150 \mathrm{~mm} \times 750 \mathrm{~mm} \times 10 \mathrm{~mm}) \mathrm{mm}$ have been prepared, cleaned and then butt welded along the joint line for friction stir welding. The geometrical dimensions are presented in Figure 1 The conical pin was designed for easy piercing of the tool to the specimen during the welding process.On an automated vertical milling machine, the welding experiments were carried out using the specially built fixture as shown in Figure 2(a), (b) to clamp the welding plates. The most critical aspect of FSW and UFSW are the required fixture design with backing plates to obstruct the raising of the plates to be welded during the welding process and to confirm the uniform distribution of temperature over the specimen plates[24]. The welding factors have been modified to create defect-free welds based on visual inspection. At tool rotational speeds of 1000 and $1800 \mathrm{rpm}$ and tool transverse speeds of $10 \mathrm{~mm} / \mathrm{min}$, welding experiments were carried out. In Figure 3 of the effective FS welded AMC plate. The observed faulty FS welded and UFS welded samples were rejected and further mechanical and microstructural characterization was undertaken.Mechanical and microstructural research was conducted on the defect-free welded plates.

Table 1. Chemical composition of 6061 Al-alloy

\begin{tabular}{llllllllll}
\hline Element & $\mathrm{Mg}$ & $\mathrm{Si}$ & $\mathrm{Fe}$ & $\mathrm{Cu}$ & $\mathrm{Mn}$ & $\mathrm{Zn}$ & $\mathrm{Cr}$ & $\mathrm{Ti}$ & $\mathrm{Al}$ \\
\hline Wt. \% & 1.1 & 0.55 & 0.4 & 0.10 & 0.9 & 0.25 & 0.04 & 0.12 & Remainder \\
\hline
\end{tabular}



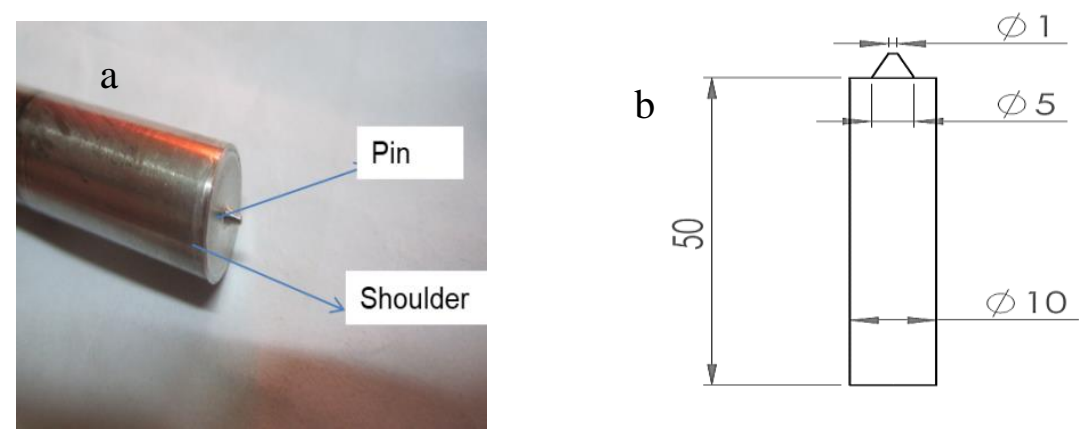

Figure 1. (a) Friction stir welding tool with a conical pin profile and (b) tool dimensions
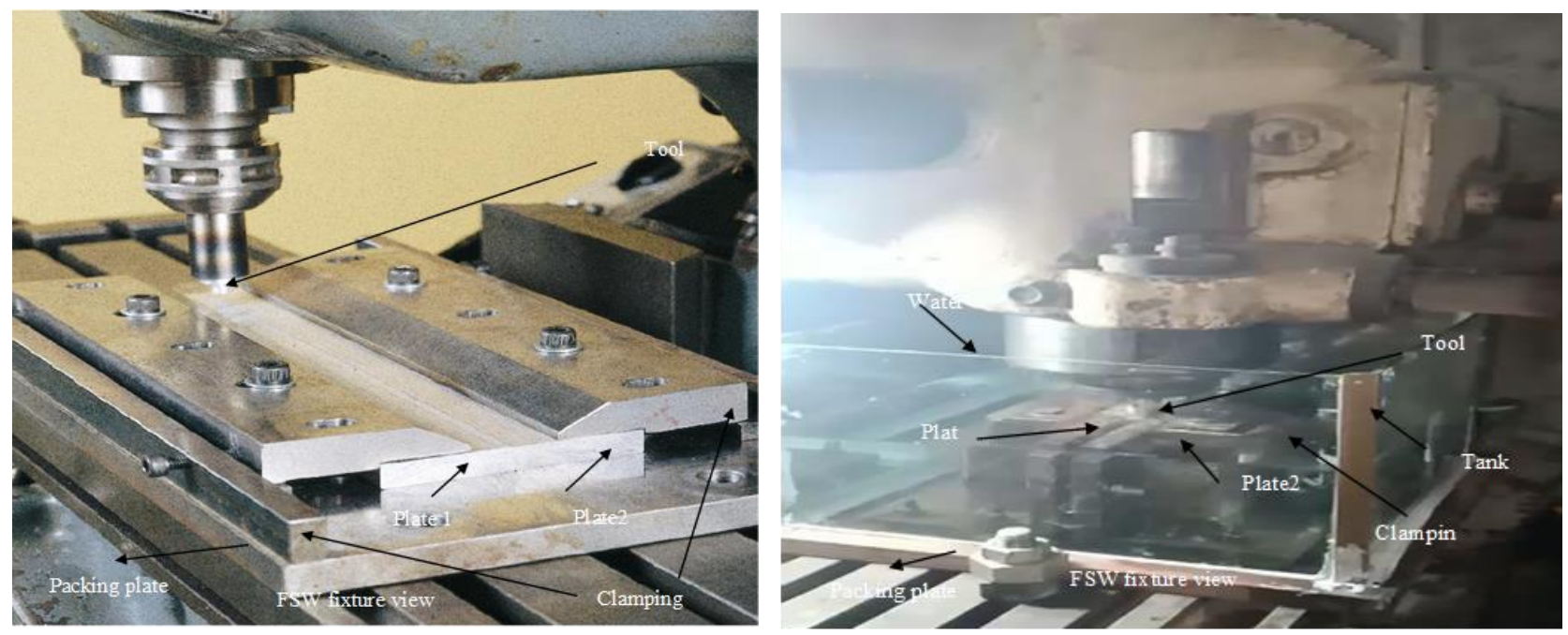

Figure 2. View of welding fixture: (a) FSW and (b) UFSW
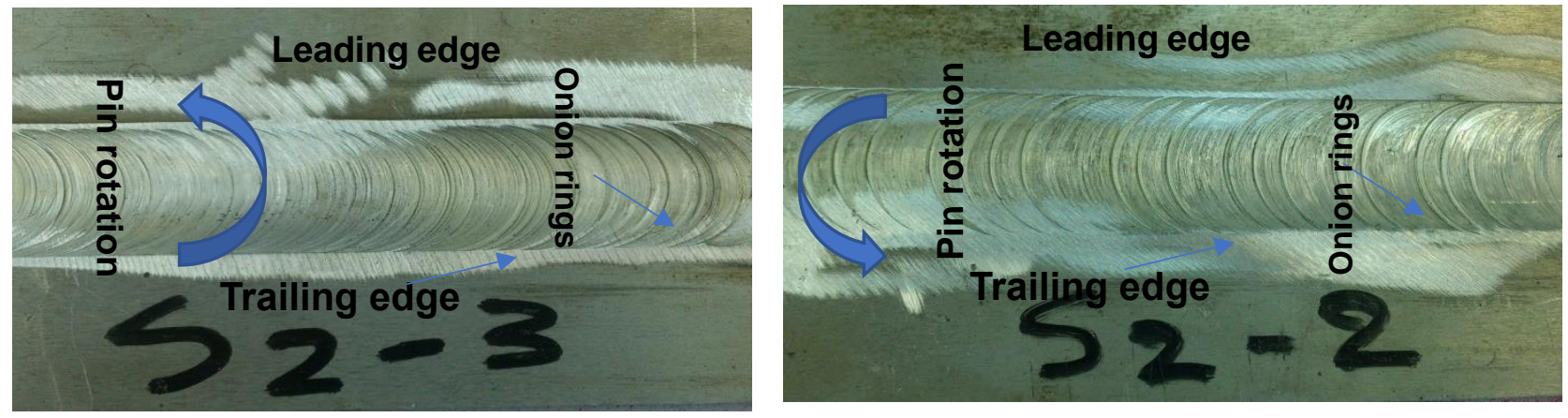

Figure 3. Aluminium matrix composite $6061 / 18 \% \mathrm{SiC}$ at: (a) UFSW and (b) FSW

\section{Material Characterization and Testing}

According to the normal metallographic technique followed by mirror polishing and etching with Keller 's reagent, $(\mathrm{HCL}+\mathrm{HF}+\mathrm{HNO} 3+$ distilled water). the metallographic specimens were prepared from 6061 aluminium matrix composite and welded 6061 aluminium matrix composites. The standard tensile specimen was slashed perpendicular to the joint line and prepared from all samples in compliance with the ASTM E8-04 standard[25]. Tensile specimens with a gauge length of $57.2 \mathrm{~mm}$, a gauge width of $12.2 \mathrm{~mm}$ and a thickness of $10 \mathrm{~mm}$ have been prepared. The tensile tests were carried out on a Blue Star universal tensile testing machine (SE UTE 200) with a maximum capacity of up to $200 \mathrm{kN}$. An optical scanning microscope (XPZ-830 T) made by China has been used to study the microstructure of FS welded specimens. The microstructural analysis of the Al-matrix stir cast as a composite cast aluminium matrix and welded joint has also been carried out in the same way. Using the FIE model VM50 Vickers microhardness tester, the microhardness test of the FS welded and other specimens (as cast matrix alloy and composite) was performed. At a constant load of $0.8 \mathrm{kgf}$ for a dwelling time of 17 seconds, thehardness measurements were carried out at different positions on both sides of the weld zone.The measurements of hardness were then defined as average micro-hardness. 


\section{RESULTS AND DISCUSSION}

Visual Inspection

Visual inspection of the upper surface of both FS welded and UFS welded sample revealed uniform semicircular surface ripples caused by the final sweep of the trailing edge of the rotating shoulder of the tool over the welded nugget, as shown in Figure 3, under the impact of the probe on the top of pressure. The existence of such surface ripples, referred to as union circles, has previously been observed by AMC's FSW and UFSW. The lower surface of weldments showed visually a uniform homogenous flat surface in the UFSW compare to FSW.

\section{Microstructural Characterization}

The FS welded and UFS welded 6061/18 wt. macro-structural inspection in Figure 4. SiC composite plate percent is illustrated. The macro-structural analysis of the welded joint showed the continuous flow from the advancing side (AS) to the retreating side (RS) of the plasticized material. The macrograph for the welded joint did not identify any defects.In this analysis, the stir zone (SZ) was observed with a basin structure as stated by others [23] . In the macrograph, as shown in Figure 4, the various parts of the welded joint such as the weld zone (WZ), the heat affected zone (HAZ), the thermomechanical affected zone (TMAZ) and the base metal (BM) are clearly defined. The weld zone and thermomechanical affected zone (TMAZ) are characterised by adjoining regions. thermomechanical affected zone (TMAZ) is that region which experienced high thermal cycles and subjected to plastic deformation under the action of thermal cycles. Weld zone (WZ) and thermomechanical affected zone (TMAZ) borderline have been characterised by the appearance of small-sized SiC reinforcing agents in the weld zone (WZ) produced due to the stirring tool action. Similar examinations have been investigated in the literature [12]. In Figure 4(a, b) displays the macroscopic cross-sections at two rotation speeds of 1000 and $1800 \mathrm{rpm}$ of the FSW, but Figure 4(c, d) displays the macroscopic cross-sections at two rotation speeds of 1000 and $1800 \mathrm{rpm}$ of the underwater friction stir welds. The nugget zone (NZ) is dynamically recrystallized and the heat created less because of the cooling rate due to the effect of the force exerted by the FSW instrument and the heat produced due to friction, but dynamically recrystallized in UFSW due to the effect of the force exerted by the UFSW instrument. The microscopic weld images at $1800 \mathrm{rpm}$ at FSW and UFSW are shown differently in Figure 4(a) and (c). Clearly evident are the three regions: base metal (BM), HAZ and TMAZ and separations thereof.The inter-metallic particles are dispersed in the HAZ region, causing the grains to be much coarser than the NZ and TMAZ grains. In comparison to the parent material, there were finely scattered spheroids with more precipitates in the recrystallized TMAZ.

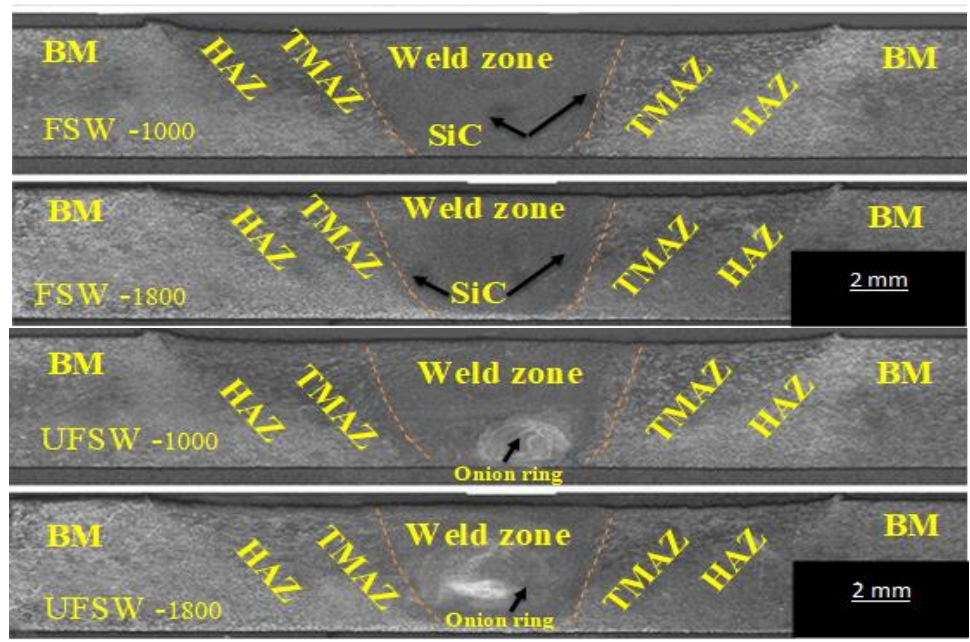

Figure 4. Macrostructure of friction stir welded for 6061 / 18\% SiC composite: (a) FSW at1000 rpm, (b) FSW at1800 rpm, (c) FSW at1000 rpm and (d) UFSW at1800 rpm

The weld zone optical microscope as shown in Figure (a-f)indicated, respectively, that no particle segregation was observed in the weld zone as stated in literature survey for welding processes aluminium matrix composite. As noted in the optical microscope images in the weld region, the chances of micro porosities associated with the stir cast composite matrix were eliminated following in UFSW and UFSW. In the welding field, a homogeneous distribution of SiCagents was found. The scale of the precipitates and their distribution in Figure 5, and Figure 6 represents the existence of three zones which are separate. The sediments are fewer compact and relatively fine at the weld centerline, though they are comparatively rough and denser in the BM. An intermediate state was observed in the boundary layer. It is worth noting that, in The boundary flow layers were swept away by the coarse particles. Sediment dissolution through heating, where the temperature has overrun $0.8 \mathrm{Tm}$, and reprecipitation through comparatively speedy cooling by water in UFSW may be the explanation for the depressed density of sediments at the weld centerline. Via shatter and degeneracy procedures, the movements in rotation of the stir probe can influence the size of sediments. Because of the thermomechanical 
mechanism of FSWand UFSW, Metallurgical transformations will be caused by together the material flow and the heat dissipation rate, changing the mechanical properties. The optical microscopic image of the HZA and NZ is shown in Figure 6(a) to (f). Two zones, NZ and HAZ, were clearly distinguishable from the optical microscopic joint weld. It is shown that from traditional FSW to UFSW, grain size is decreased. It has been It's been deliberate The complex recrystallization and recovery of aluminum alloys plays an important role in the grain size of the welded region in FS [26], [27]; hus, at the same time, the application of vibration and cooling results in high angle grain boundaries because higher dislocation density and dynamic recovery and finally fine grain size. This implied the need to examine the mechanical characteristics of the joint because of the unusual apportionment of the material in the WZ.
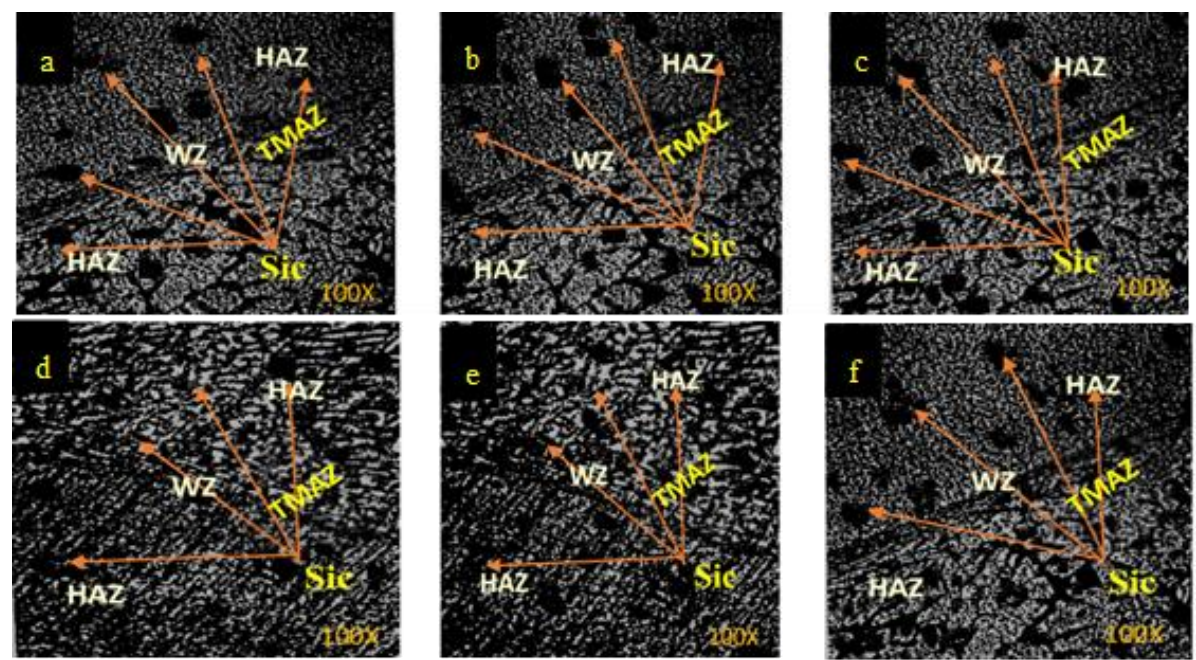

Figure 5. Optical microscopic of FSW for composite material at:-(a) $1000 \mathrm{rpm}$ and 6061/5\% SiC, (b) $1000 \mathrm{rpm}$ and $6061 / 10 \% \mathrm{SiC}$, (c) $1000 \mathrm{rpm}$ and $6061 / 18 \% \mathrm{SiC}$ min, (d) $1800 \mathrm{rpm}$ and 6061/5\% $\mathrm{SiC}$, (e) $1800 \mathrm{rpm}$ and 6061/10\% $\mathrm{SiC}$ and (f) $1800 \mathrm{rpm}$ and $6061 / 18 \% \mathrm{SiC}$
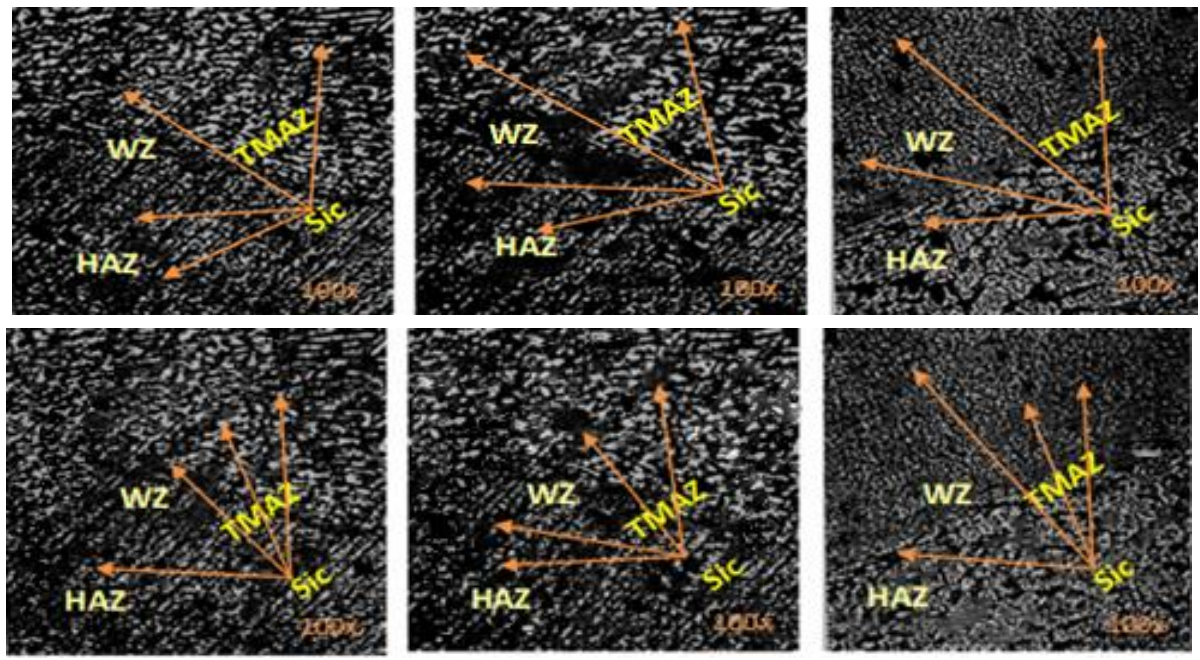

Figure 6. Optical microscopic of UFSW for composite material at: (a) $1000 \mathrm{rpm}$ and 6061/5\% SiC, (b) $1000 \mathrm{rpm}$ and $6061 / 10 \% \mathrm{SiC}$, (c) $1000 \mathrm{rpm}$ and 6061/18\% $\mathrm{SiC}$, (d)1800 rpm and 6061/5\% $\mathrm{SiC}$, (e) $1800 \mathrm{rpm}$ and 6061/10\% $\mathrm{SiC}$ and(f) $1800 \mathrm{rpm}$ and $6061 / 18 \% \mathrm{SiC}$

\section{Mechanical Characterization}

As shown in Figure 7, the hardness profiles for FSW and UFSW specimens were measured a cross section of the weld zone at $10 \mathrm{~mm} / \mathrm{min}$ and at two rotational speeds of $1000 \mathrm{rpm}$ and $1800 \mathrm{rpm}$. At three separate positions a cross the weld nugget, i.e. near the weld-face, halfway through the weld nugget, and near the root of the friction stir weld joint, the hardness profiles were taken. The stir region is subjected to extreme plastic deformation during the friction stir welding process and the movement of viscous material takes place in the plastic state around the tool pin due to the stirring motion of the tool. For grain refinement, the generation of heat due to friction during the FSW and UFSW process is responsible. The stirring motion of the instrument pin carries the surface of $\mathrm{SiC}$ agents and there is a reduction in the scale of SiC agents. The presence of such numerous fragmented small and rounded SiCe agents with Al-matrix grain size refinement greatly improved the welds' mechanical characteristics. Hardening of the composite matrix has also greatly increased the hardness in the weld zone after FSW and UFSW. The hardness of the Vickers along the cross section of the weld is 
shown in Figure7. Obviously, the show of thermal softening during FSW, and UFSW has induced a decline in hardness relative to BM. Hardness across various areas such as NZ, HAZ and TMAZ was found to have a substantial differential between UFSW and FSW. That is to add, the hardness of the specimens referring to UFSW is greater than that of FSW. Compared to the FSW phase, the softened area consisting of NZ, and HAZ is narrow in UFSW method. For UFSW and FSW, the NZ hardness are $73 \mathrm{Hv}$ and $65 \mathrm{Hv}$, respectively. In UFSW, this rise in hardness in the stir zone is attributed to the presence of precipitates in the alloy and finer grains. Hardness is usually imparted by the precipitate distribution, high dislocation rate, grain size, for the case of a precipitate hardened Al 6061/18 wt.\% SiC composites. Sudden lack of heat and deformation are the key factor stopping SiCe precipitates from coarsening. The cooling rate and vibration both plays a major role in improving the hardness. As a consequence, spontaneous cooling rate and vibration in UFSW, where the specimen and the procedure are done within the water, is one of the reasons for imparted the hardness in the weld zone. Heating accompanied with rapid cooling can induce metallurgical transmutations. Hardness is therefore on the rise [17]. The heat produced at the tool sample interface and the cooling rate and vibration are main factors influencing the hardness that are actually the cause for grain refining and immediate forming. Sample welded with UFSW are cooled with underwater, whereas those welded with standard FSW are collided with air. In the former, temperature increase is stopped as the operation is done underwater and further grain processing is impeded. Nevertheless, grain is coarser in the latter for a long time owing to heat exposure. In exchange, the dislocation rate can decrease the hardness in the stir region considerably.

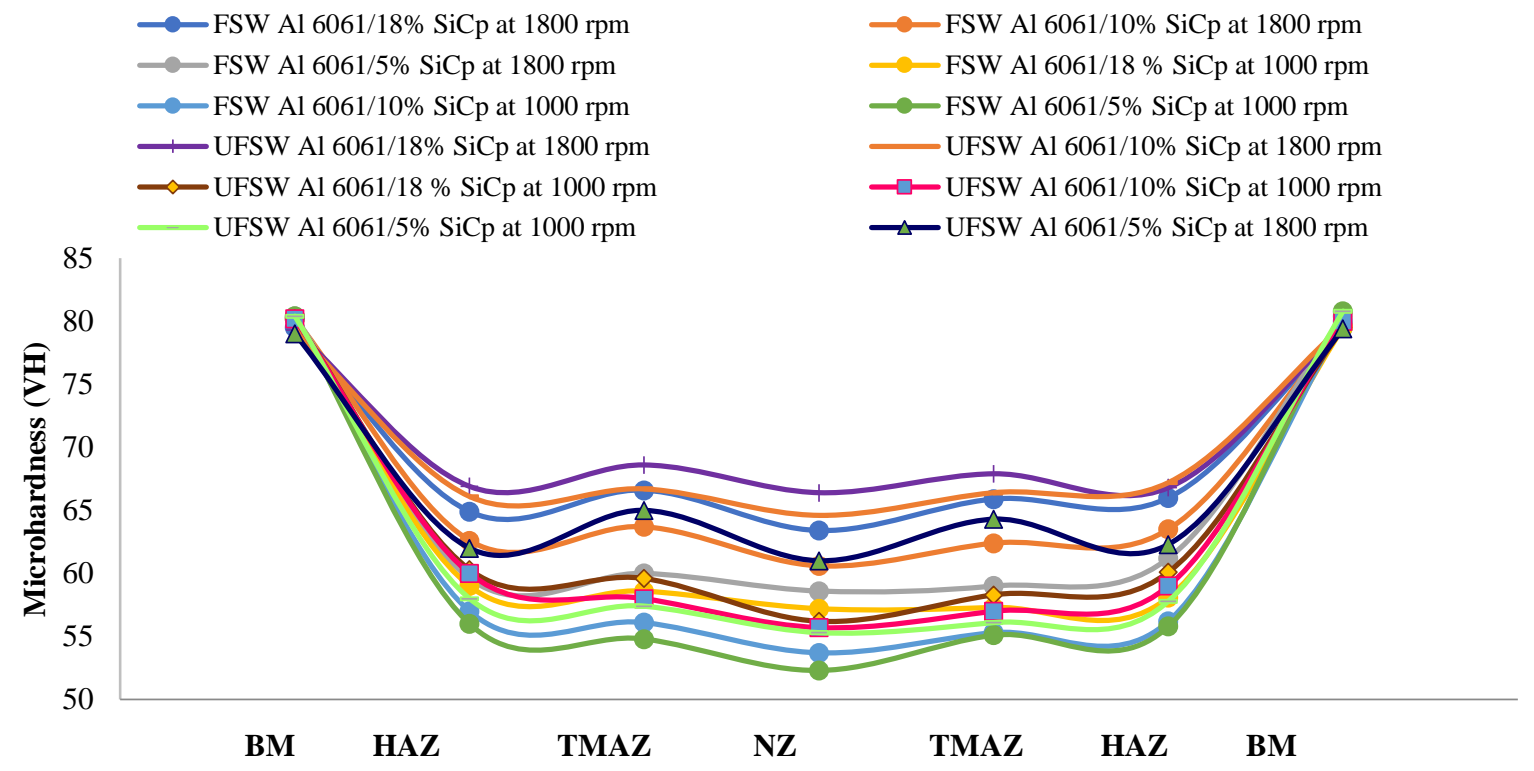

Figure 7. Microhardness across the welded joint 6061 and base metal 6061 at addition different \%SiC

The tensile behaviour of the 6061 composite matrix and 6061/5 percent $\mathrm{SiC}$ welded, 6061/10\% SiC welded by FSW, UFSW and 6061/18 percent SiC welded joints are shown in Figure 8. By reinforcing SiC agents in the Al-matrix alloy, the tensile strength of the welded joint was remarkably increased. Because of the difference in the thermal expansion coefficient between $\mathrm{SiC}$ reinforcing agents and the aluminium matrix alloy, an increase in dislocation density was observed. Figure 8 At this point,yield strength starts to saturate as reinforcement because of multiplication of dislocation and dynamic recovery because of rearrangement of dislocation enter a stable equilibrium. As a consequence, the disfigurement happens in a constant-state setting, where a material's yield strength intensity does not alter significantly with the strain. It is found that UFSW gives the maximum ultimate tensile strength (UTS) and ductility as opposed to other welding provides. displays a diagram of welded objects with various welding conditions. A detailed analysis of this image indicates that the overall tensile strength (UTS) is higher for welded materials for $\mathrm{Al} 6061 / 18 \%$ SiC at FSW and UFSW compared to $\mathrm{Al} 6061$ due to the precipitate $\mathrm{SiC}$, while the cooling rate in UFSW produced improved the ultimate tensile strength. In FSW and UFSW the yield strength of the substance rises at the initial stage of deformation when dislocation multiplies and interacts. However, with the rise in dislocation intensity the recovery rate often rises, and Lowangle boundaries tend to be rearranged and formed by dislocations as sub grains expand [28 - 29]. 


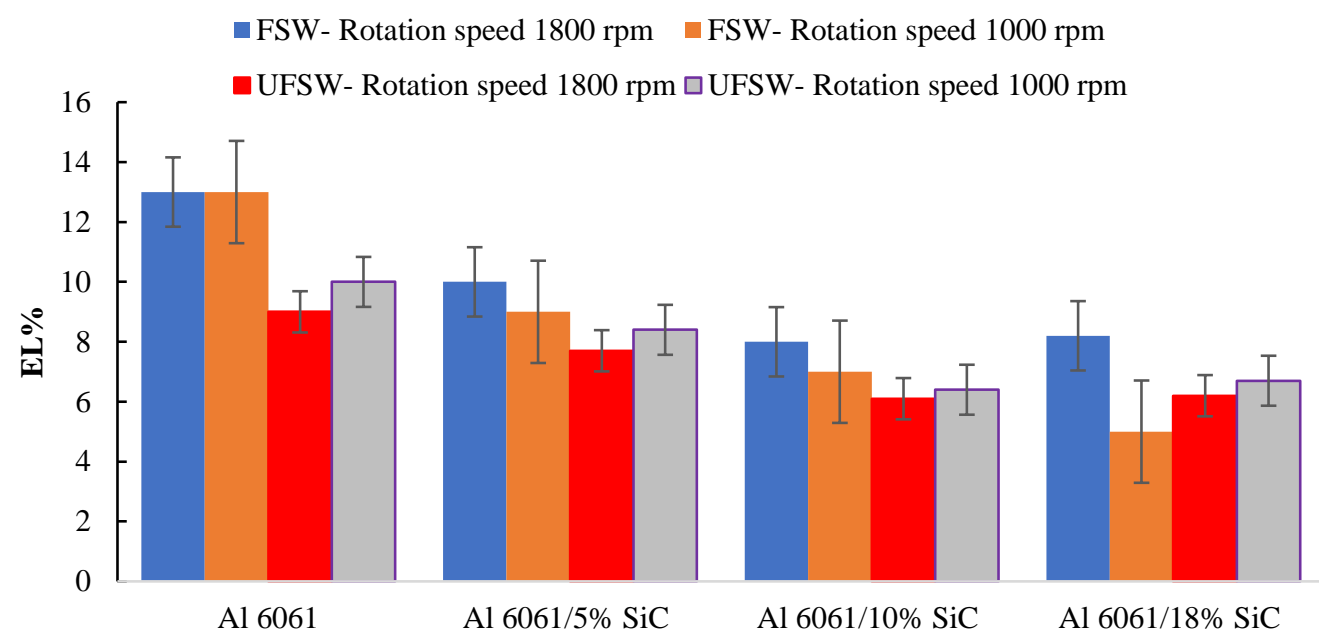

Figure 8. Ultimate tensile strength behavior of Al 6061, welded 6061/5\% SiC, welded $606110 \% \mathrm{SiC}$ and welded $606118 \% \mathrm{SiC}$

The percentage elongation for Al6061 is $13 \%$, while for those specimens welded using and FSW it is $8.2 \%$ and 6.7 $\%$. More percentage elongation was shown by joints using FSW and UFSW than those welded using UFSW. This is assumed to be Due to the disintegration of SiCe reinforcing agents and, following friction stir welding, the formation of the fine grain structure in the WZ. The results are expected, as shown in Figure 9, as the percent wt. SiCe elongation increases and decreases [30-32]. This is due to a decline in ductility due to an increase in tensile strength, as seen above in Figuer 8.

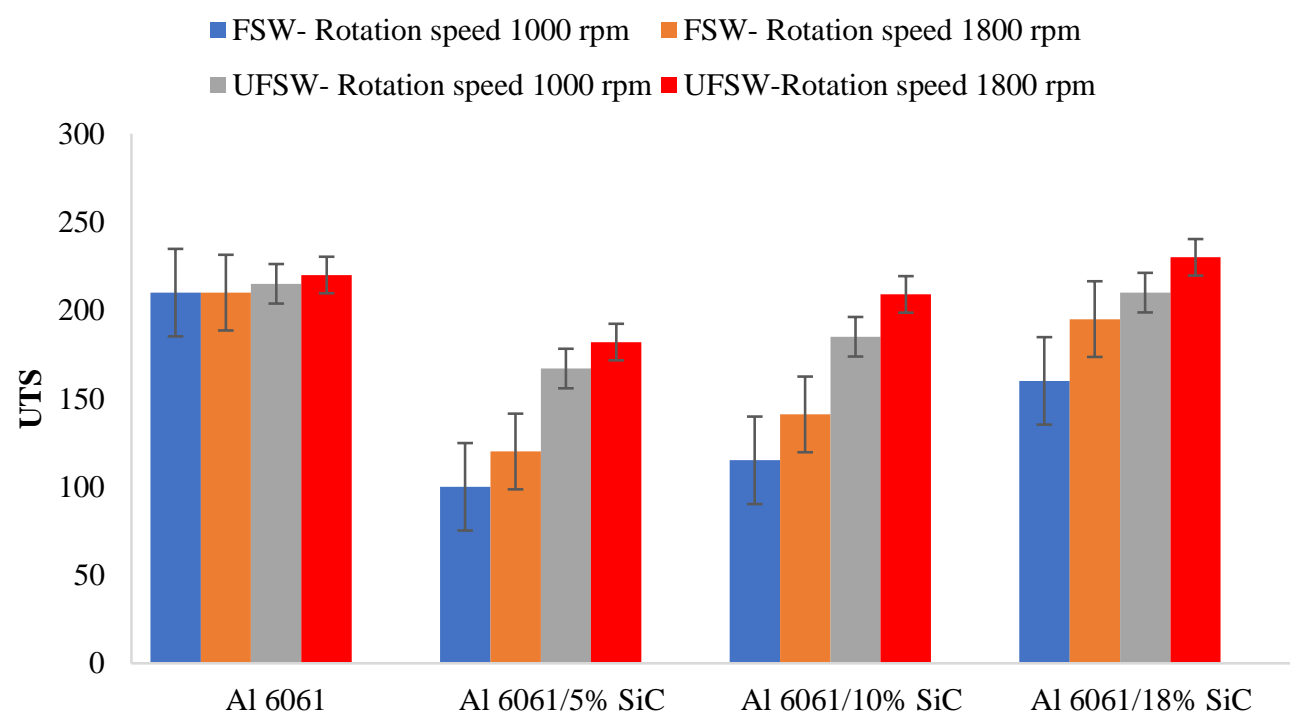

Figure 9. Elongation behavior (\%) of Al 6061, welded 6061/5\% SiC, welded $\mathrm{Al} 6061$ 10\% SiC and welded $\mathrm{Al} 6061$ $18 \% \mathrm{SiC}$

\section{CONCLUSIONS}

Experimental investigations were conducted on $\mathrm{Al} 6061, \mathrm{Al} 6061 / 5, \mathrm{Al} 6061 / 10$, and $\mathrm{Al} 6061 / 18$ wt. \%SiC composites FSW in traditional and water media at two rotation speed. From the experimental findings and studies, the following conclusions can be drawn:

1. Using friction stir welding and underwater friction stir welding methods, quality joining $\mathrm{Al} 6061 / 5, \mathrm{Al} 6061 / 10$, and $\mathrm{Al} 6061 / 18$ wt. \% SiC composites welds were able to produce.

2. Tensile strength increased with the increase in tool rotational speed at $1800 \mathrm{rpm}$ for $\mathrm{Al} 6061 / 18 \mathrm{wt} \% \mathrm{SiC}$ composites reaching a maximum and it decreased with the $\mathrm{Al}$ 6061/5 and $\mathrm{Al}$ 6061/10, wt. \% SiC composites

3. The tensile at tool rotational speed of $1800 \mathrm{rpm}$, the maximum tensile strength of $189.9 .9 \mathrm{MPa}$ produced by FSW of the joints was obtained, while the maximum tensile strength of $230 \mathrm{MPa}$ of the joints produced by UFSW was obtained at tool rotational speed of $1800 \mathrm{rpm}$. 
4. Strength of UFSW joints was higher than FS welded joints, indicating better tool interaction with welding Al 6061/18 wt. \% SiC composites .

5. UFSW joint strength was higher than FS welded joints, indicating better interaction of the tool with welding Al 6061/18 wt. \%SiC.

6. In the underwater FSW, fine grains were obtained at the weld cross-section. The microhardness profile has a standard form in both FSW and UFSW, with the latter having greater hardness.

7. Via visual inspection of welded $\mathrm{Al} 6061 / 18$ wt. a tunnel defect form could not be seen at FSW and UFSW . There are no defects noted by macroscopic inspection of the $\mathrm{Al} 6061 / 5 \mathrm{wt}$ \% $\mathrm{SiC}$. No defects are noticed by macroscopic examination of the structure in the $\mathrm{Al} 6061 / 5 \mathrm{wt}$. \% SiC, Al 6061/10 wt. \% SiC, Al 6061/18 wt. \% $\mathrm{SiC}$ cross- section but found $\mathrm{SiC}$ concentration in FSW.

\section{REFERENCES}

[1] S. K. Ghosh and P. Saha, "Crack and wear behavior of SiC particulate reinforced aluminium based metal matrix composite fabricated by direct metal laser sintering process," Materials and Design, vol. 1, no. 32, pp. 139-145, 2011, doi: 10.1016/J.MATDES.2010.06.020.

[2] J. v Foltz, "Metal-Matrix Composites," In ASM International, Metals Handbook, Properties and Selection:," Nonfe. Alloys and Special-Purp., Mate., vol. 10, no. 2, pp. 901-903, 1990.

[3] I. Sabry, M. A. Ghafaar, A. H. I. Mourad, and A. H. Idrisi, "Stir casted SiC-Gr/Al6061 hybrid composite tribological and mechanical properties," SN Applied Sciences, vol. 2, no. 5, pp. 1-8, 2020, doi: 10.1007/S42452-020-2713-4/FIGURES/8.

[4] S. Scudino et al., "Mechanical properties of Al-based metal matrix composites reinforced with Zr-based glassy particles produced by powder metallurgy," Acta Materialia, vol. 57, no. 6, pp. 2029-2039, 2009, doi: 10.1016/J.ACTAMAT.2009.01.010.

[5] M. Rosso, "Ceramic and metal matrix composites: Routes and properties," J. of Mate. Proce. Techn., vol. 17, pp. 364-375, 2006.

[6] T. Prater, "Solid-state joining of metal matrix composites: A survey of challenges and potential solutions," Mate. and Manuf. Proc., vol. 26, no. 4, pp. 636-648, 2011, doi: 10.1080/10426914.2010.492055.

[7] D. Storjohann, O. M. Barabash, S. S. Babu, S. A. David, P. S. Sklad, and E. E. Bloom, "Fusion and friction stir welding of aluminum-metal-matrix composites," Metall. Mater. Trans. A, vol. 36, no. 11, pp. 3237-3247, 2005, doi: 10.1007/S11661005-0093-4.

[8] S. Amini and M. R. Amiri, "Study of ultrasonic vibrations' effect on friction stir welding," The International Journal of Advanced Manufacturing Technology, vol. 73, no. 1, pp. 127-135, 2014, doi: 10.1007/S00170-014-5806-7.

[9] W. Xi-He, N. Ji-Tai, G. Shao-Kang, W. Le-Jun, and C. Dong-Feng, "Investigation on TIG welding of SiCp-reinforced aluminum-matrix composite using mixed shielding gas and Al-Si filler," Materials Science and Engineering A, vol. 499, no. 1-2, pp. 106-110, 2009, doi: 10.1016/J.MSEA.2008.07.037.

[10] S. G. Wang, X. H. Ji, X. Q. Zhao, and N. N. Dong, "Interfacial characteristics of electron beam welding joints of SiCp/Al composites," Mate. Sci. and Tech., vol. 27, no. 1, pp. 60-64, 2013, doi: 10.1179/174328409X412005.

[11] G. Çam, "Friction stir welded structural materials: Beyond Al-alloys," International Materials Reviews, vol. 56, no. 1, pp. 148, 2011, doi: 10.1179/095066010X12777205875750.

[12] I. Sabry and A. M. El-Kassas, “An appraisal of characteristic mechanical properties and microstructure of friction stir welding for Aluminium 6061 alloy - Silicon Carbide (SiCp) metal matrix composite," Journal of Mechanical Engineering and Sciences, vol. 13, no. 4, pp. 5804-5817, 2019, doi: 10.15282/JMES.13.4.2019.07.0463.

[13] P. L. Threadgilll, A. J. Leonard, H. R. Shercliff, and P. J. Withers, "Friction stir welding of aluminium alloys," Inter. Mate. Reviews., vol. 54, no. 2, pp. 49-93, 2013, doi: 10.1179/174328009X411136.

[14] N. Gadallah, I. Sabry, and M. A. Ghafaar, "A summarized review on friction stir welding for Aluminum alloys," The Academic Research Community publication, vol. 4, no. 1, 2020, doi: 10.21625/archive.v4i1.695.

[15] X. G. Chen, M. da Silva, P. Gougeon, and L. St-Georges, "Microstructure and mechanical properties of friction stir welded AA6063-B4C metal matrix composites," Materials Science \& Engineering A, vol. 1-2, no. 518, pp. 174-184, 2009, doi: 10.1016/J.MSEA.2009.04.052.

[16] N. Kaushik, S. Singhal, Rajesh, P. Gahlot, and B. N. Tripathi, "Experimental investigations of friction stir welded AA6063 aluminum matrix composite," Journal of Mechanical Engineering and Sciences, vol. 12, no. 4, pp. 4127-4140, 2018, doi: 10.15282/JMES.12.4.2018.11.0357.

[17] I. Sabry, A.-H. I. Mourad, and D. T. Thekkuden, "Comparison of mechanical characteristics of conventional and underwater friction stir welding of AA 6063 pipe joints," International Review of Mechanical Engineering, vol. 14, no. 1, 2020, doi: 10.15866/ireme.v14i1.17483.

[18] I. Sabry and N. Zaafarani, "Dry and underwater friction stir welding of aa6061 pipes - A comparative study," IOP Conference Series: Materials Science and Engineering, vol. 1091, no. 1, p. 012032, 2021, doi: 10.1088/1757-899X/1091/1/012032.

[19] H. J. Liu, H. J. Zhang, Y. X. Huang, and L. Yu, "Mechanical properties of underwater friction stir welded 2219 aluminum alloy," Transactions of Nonferrous Metals Society of China (English Edition), vol. 20, no. 8, pp. 1387-1391, 2010, doi: 10.1016/S1003-6326(09)60309-5. 
[20] R. P. Mahto, C. Gupta, M. Kinjawadekar, A. Meena, and S. K. Pal, "Weldability of AA6061-T6 and AISI 304 by underwater friction stir welding," Journal of Manufacturing Processes, vol. 38, pp. 370-386, 2019, doi: 10.1016/J.JMAPRO.2019.01.028.

[21] Q. Wang, Z. Zhao, Y. Zhao, K. Yan, and H. Zhang, "The adjustment strategy of welding parameters for spray formed 7055 aluminum alloy underwater friction stir welding joint," Materials \& Design, vol. 88, pp. 1366-1376, 2015, doi: 10.1016/J.MATDES.2015.09.038.

[22] D. Paramaguru, S. R. Pedapati, M. Awang, H. Mohebbi, and K. V. Sharma, "Effect of process parameters on mechanical properties of AA5052 joints using underwater friction stir welding," Journal of Mechanical Engineering and Sciences, vol. 14 , no. 1, pp. 6259-6271, 2020, doi: 10.15282/JMES.14.1.2020.05.0490.

[23] K. Kalaiselvan, I. Dinaharan, and N. Murugan, "Characterization of friction stir welded boron carbide particulate reinforced AA6061 aluminum alloy stir cast composite," Materials and Design, vol. 55, pp. 176-182, 2014, doi: 10.1016/J.MATDES.2013.09.067.

[24] M. M. Hasan, M. Ishak, and M. R. M. Rejab, "A simplified design of clamping system and fixtures for friction stir welding of aluminium alloys," Journal of Mechanical Engineering and Sciences, vol. 9, pp. 1628-1639, 2015, doi: 10.15282/JMES.9.2015.10.0158.

[25] I. Sabry, N. Gad Allah, M. A. Nour, and M. Abdel Ghafaar, "Mechanical characteristic of Al 6063 pipe joined by underwater friction stir welding," Proceeding of Fourth International Conference on Inventive Material Science Applications, pp. 689699, 2022, doi: 10.1007/978-981-16-4321-7_56.

[26] B. Bagheri, A. A. Mahdian Rizi, M. Abbasi, and M. Givi, "Friction stir spot vibration welding: Improving the microstructure and mechanical properties of A15083 joint," Metallography, Microstructure, and Analysis, vol. 5, no. 8, pp. 713-725, 2019, doi: 10.1007/S13632-019-00563-Y.

[27] A. M. El-Kassas, I. Sabry, A. H. I. Mourad, and D. T. Thekkuden, "Characteristics of potential sources - vertical force, torque and current on penetration depth for quality assessment in friction stir welding of AA 6061 pipes," International Review of Aerospace Engineering, vol. 12, no. 4, pp. 195-204, 2019, doi: 10.15866/IREASE.V12I4.16362.

[28] I. Sabry, N. E. El-Zathry, F. T. El-Bahrawy, and M. Abdel Ghaffar, "Extended hybrid statistical tools ANFIS- GA to optimize underwater friction stir welding process parameters for ultimate tensile strength amelioration," 3rd Novel Intelligent and Leading Emerging Sciences Conference (NILES), pp. 59-62, 2021, doi: 10.1109/NILES53778.2021.9600552.

[29] G. Casalino, S. L. Campanelli, N. Contuzzi, A. Angelastro, and A. D. Ludovico, "Laser-assisted friction stir welding of aluminum alloy lap joints: Microstructural and microhardness characterizations," Proceeding of SPIE - The International Society for Optical Engineering, vol. 8963, pp. 256-263, 2014, doi: 10.1117/12.2042215.

[30] I. Sabry, A. M. El-Kassas, A.-H. I. Mourad, D. T. Thekkuden, and J. A. Qudeiri, "Friction stir welding of T-joints: Experimental and statistical analysis," Journal of Manufacturing and Materials Processing, vol. 3, no. 2, 2019, doi: 10.3390/jmmp3020038.

[31] I. Sabry, A. H. Idrisi, and A.-H. I. Mourad, "Friction stir welding process parameters optimization through hybrid multi-criteria decision-making approach," International Review on Modelling and Simulations, vol. 14, no. 1, 2021, doi: 10.15866/iremos.v14i1.19537.

[32] I. Sabry, "Experimental and statistical analysis of possibility sources - Rotation speed, clamping torque and clamping pith for quality assessment in friction stir welding," Management and Production Engineering Review, vol. 12, pp. 84-96, 2021, doi: 10.24425/MPER.2021.138533. 